\title{
INMIGRACIÓN, ETNICIDAD Y PLURALISMO CULTURAL
}

\section{MARÍA DOLORES VARGAS LLOVERA}

Area de Antropología.

Universidad de Alicante.

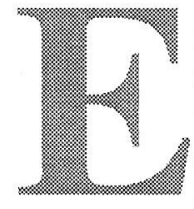

n los últimos años, se ha extendido entre la opinión pública de nuestro país la imagen de una invasión de inmigrantes provenientes, sobre todo, del continente africano. Inmigración forzada por el imparable crecimiento de la población de estos países y el alto índice de subdesarrollo.

Las migraciones no son sólo un cambio de personas de un lugar a otro, sino, también, un cambio en sus estructuras sociales y culturales: costumbres, tradiciones, valores, creencias, lengua... y todo lo que representa su mundo material y simbólico.

El proceso migratorio está caracterizado por tres períodos diferenciadores.

En primer lugar, la salida de los inmigrantes de su país provocada por situaciones carenciales de primera necesidad. El emigrante espera que la llegada a ese destino de esperanza logre acabar con las privaciones y miserias que han llenado su vida hasta el momento de emprender la emigración.

En segundo lugar, la llegada al nuevo país, que supone para toda persona un cambio que le provoca una situación de crisis ante la posibilidad de que no pueda adaptarse, o no pueda asimilar la nueva cultura.

En tercer lugar, el inmigrante se enfrenta a la gran dificultad que supone el cambio de sus valores y creencias, es decir, a la lucha entre la aceptación de un nuevo sistema de valores y el abandono paulatino de los suyos. En la mayoría de los casos, el inmigrante se aísla e intenta que la nueva cultura no rompa con su identidad.

La migración expone al individuo que la experimenta, a pasar por estados de desorganización, que exigen una reorganización ulterior, que no siempre se logra (Grimberg y Grimberg, 1984:26).

Una vez que el inmigrante llega a la sociedad receptora, difícilmente puede reorganizar su universo al encontrarse con unos parámetros sociales y culturales que le son ajenos. Así, las migraciones son hechos traumáticos que configuran una realidad social de nuestro tiempo. Por un lado, los inmigrantes rompen con su grupo de pertenencia y, por otro, la sociedad de acogida los ve llegar como intrusos, desconfía de ellos y, en muchos casos, aflora un sentimiento de rechazo. 
La sociedad de acogida provoca en el inmigrante procesos de gran conflictividad social y cultural. El impacto de las dos culturas, hasta que llega el momento de una mutua asimilación, conlleva graves dificultades de convivencia. Se le obliga a ir cambiando su identidad cultural por la necesidad de supervivencia, al mismo tiempo, tiene que recomponer sus estructuras simbólicas, siempre que su capacidad se lo permita. De lo contrario caerá dentro de posiciones sociales marginales y de una periferia cultural. (Oliver, Vargas y otros, 1993:254)

Las relaciones entre las actuales minorías de inmigrantes y la sociedad receptora no se encuentran en un nivel igualitario. Más bien al contrario, ambos son grupos sociales diferenciados, no sólo económicamente, sino por el complejo mundo cultural: cada uno es portador de su propia cultura, lo que favorece, a partir de esta diferencia, que los inmigrantes se encuentren bajo factores marginales que incluye una profunda subordinación social.

La cultura es un mecanismo de adaptación que hace posible que los seres humanos se sientan satisfechos con lo que les ha proporcionado el entorno donde han nacido y se han desarrollado, cubren así las necesidades básicas que su cultura ha estructurado.

El inmigrante, en su lugar de origen, se encuentra adaptado culturalmente en el mundo que le rodea. Ha sido su precaria economía lo que le lleva a emprender la migración. Y es a partir de este momento cuando su mundo cultural y su mundo simbólico se empieza a desequilibrar al incorporarse a sociedades que poco, o nada, tienen que ver con su forma de vivir. Su particularismo cultural comienza a derrumbarse para dar paso a la aceptación de nuevas formas de convivencia que quizás le empuje a una posible integración en su nueva sociedad. Este hecho, de producirse, le va a determinar una difícil dualidad cultural.

En su nuevo mundo, el inmigrante crea unas pautas intermedias entre su forma de vivir y la que encuentra en su nueva residencia, optando por un estilo propio que no encaja con la realidad social que le rodea, en lo que podríamos llamar una conducta colectiva derivada de la inmigración.

La comunicación entre los dos grupos, es decir, entre los inmigrantes y la sociedad de acogida, alumbra el nacimiento y aparición de grupos étnicos diferenciados, que conlleva, al mismo tiempo, un cambio en las estructuras de clase, además de la identificación de su propia cultura.

En sus países de origen, los inmigrantes, se encuentra bien delimitados en su clase social. Al emigrar e incorporarse a otra sociedad, acceden directamente a una clase inferior, generalmente subordinada y separada de la clase obrera del país, aunque puede darse el caso de que, aun conviviendo en los mismos asentamientos, nazca una barrera invisible que los separe social y culturalmente, formando una clase dividi- 
da dentro de la misma clase. Aparecen, de esta manera, los ghetos de inmigrantes que servirán como focos de recepción a otros nuevos, al ponerse en marcha las redes sociales de parentesco y amistad.

La inmigración de hoy día a la Europa industrial no sólo la componen personas con una economía insuficiente, mejor dicho, sin ninguna economía, sino que llevan consigo la ilegalidad y la raza o el racismo, aunque para no emplear estas última palabras empleemos las de etnia y etnicidad. Según Moreno Feliu (1994), es un ambiguo tercer término que cuenta entre sus referentes tanto con las viejas nociones maquilladas de raza-pueblo como con la abstracción más purificada de la esencia: la etnicidad. Vuelve a existir la «pureza étnica» como en otros tiempos existió la «pureza racial» y la «pureza de sangre».

Pero ¿qué entendemos por etnia? Esteva Fabregat considera que etnia es una comunidad cultural localizada y consciente de su identidad mediante consciencia de su singularidad, y por lo tanto de su diferenciación como forma de cultura respecto de otras $u$ otras comunidades. (Esteva, 1984:5)

Los conceptos de cultura y etnia -siguiendo a este mismo autorson históricamente parte de una identidad y de una doble definición: la que resulta del modo como uno define su propio yo cultural ante otros, y la que resulta del modo como éstos le definen a uno. Ambas definiciones son parte del contexto de identidad. (Esteva, 1984:6).

Las etnias en los países europeos ya no significan exclusivamente las diferencias entre las propias regiones. Actualmente, hablar de etnia, etnias o etnicidad está ligado inexorablemente a la inmigración y, es más, al llamado Tercer Mundo y quizás nos podríamos hacer esta pregunta: ¿están los japoneses incluidos en lo que el mundo occidental llama grupos étnicos? En el sentido en que la sociedad actual lo entendemos, no. Aunque en el Japón sí existen diferentes grupos culturales.

Si nos situamos en el contexto de cada grupo étnico o cultural y de unas mutuas relaciones de igualdad, nos encontramos en un proceso de evolución cultural diferenciado y sin ninguna conflictividad. Pero si por el contrario, asistimos a procesos donde una cultura o sociedad por sus circunstancias económicas, o de procesos de evolución técnica, científica y/o cultural, como en los actuales países desarrollados, observaremos que las minorías étnicas venidas de países subdesarrollados sufren procesos de rechazo, de aculturación y de marginación entre otros, acabando, en muchas ocasiones, en graves conflictos sociales, sin olvidar las que se producen a diario en la vida cotidiana.

No sólo en las sociedades urbanas industriales, sino también en el mundo rural de estas mismas sociedades, se da el mismo requisito social que, con el tiempo, desemboca en antagonismo, al tratar cada unidad étnica de mantener su particularismo cultural. 
La unión y convivencia de distintos sistemas culturales determina la interacción de diferentes formas de vida, que deberían desarrollar y estimular los intercambios de experiencias, y la creación de una sociedad pluricultural o pluriétnica dentro de una convivencia respetuosa y sin conflictos, pero la realidad actual no lleva ese camino, más bien el contrario; siguen siendo las sociedades uniétnicas las que mantienen sus estructuras sociales, sin que dentro de ellas se fomente una conflictividad tan grave como cuando se trata de relaciones con otras culturas

Cada grupo cultural, indistintamente que se encuentre dentro o fuera de su país de origen, defiende su identidad y pretende un reconocimiento social externo. En las actuales emigraciones existen los grupos dominadores y los grupos subordinados. Está claro que los primeros, los dominadores, son los que representan las sociedades de acogida y los segundos, los subordinados, los inmigrantes venidos del llamado Tercer Mundo. Ambos pretenden su afirmación social, y al no producirse un entendimiento entre estas dos posiciones, nace la incomprensión y la no tolerancia.

Nadie debe poner en duda que cada cultura o grupo étnico posee su propio ethos o juego de valores. Se debe buscar un modelo que progresivamente desemboque en sociedades poliétnicas y entender profundamente el significado del pluralismo cultural.

El concepto de pluralismo cultural es de vital importancia para acceder al entendimiento entre grupos socialmente diferentes.

El pluralismo se asocia, según Van Den Berghe, a las siguientes características:

1) Una relativa ausencia de consenso en los valores.

2) Una relativa presencia de heterogeneidad cultural.

3) Una relativa presencia de conflictos entre grupos sociales de significación.

4) Una relativa autonomía entre las partes del sistema social.

5) Una relativa importancia de coacción e interdependencia económica como base de la integración social.

6) Un dominio político ejercido por uno de los grupos sociales sobre los demás. (Van Den Berghe,1971:67)

La realidad de estos puntos nos lleva, sin lugar a duda, a la radicalización del entendimiento entre las diferentes identidades culturales. Queda claro que los puntos de Van Den Berghe dan a la sociedad dominadora, en nuestro caso la sociedad de acogida, todas las ventajas para mantener y defender sus posiciones de predominio social y cultural.

Hacer un distinción entre pluralismo cultural y social es útil dentro de las sociedades receptoras de inmigrantes. El pluralismo cultural es el resultado de la presencia de varios grupos étnicos bien distinguibles 
entre sí, y de una misma tradición cultural. Sin embargo, el pluralismo social se halla presente hasta tal punto que una sociedad está dividida estructuralmente en conjuntos de instituciones y en grupos sociales diferenciados sobre bases culturales

En la práctica, según Van Den Berghe (1971), el pluralismo cultural y social, a menudo, van de la mano y pueden así considerarse como dos facetas del mismo fenómeno. Pero la distinción analítica sigue siendo útil, pues el pluralismo cultural casi invariablemente va acompañado del pluralismo social, éste último puede encontrarse en ausencia casi total del pluralismo cultural.

Las relaciones que derivan tanto del pluralismo social como del pluralismo cultural presentan dificultades íntimamente ligadas a las relaciones interétnicas. De los grupos diferenciados étnicamente, nace lo que hoy podemos llamar pluralismo étnico, que se caracteriza por una heterogeneidad social y cultural de difícil conexión entre sí.

El triunfo social y cultural de un grupo étnico, incluyendo la sociedad de acogida, rompe con la pluralidad y la esperanza de una convivencia poliétnica. «Quedan destruidas, al nacer», como afirma Van Den Berghe (1971), un máximo y un mínimo de pluralismo cultural.

En el caso de la inmigración a Europa, los máximos son las sociedades receptoras, con sus propias diferencias entre nacionalidades y regiones y los mínimos son las personas migrantes con sus propias diferencias sociales y culturales.

Sin embargo, ante el rechazo de los actuales movimientos migratorios, con la formación de grupos étnicos estables, y de todos los particularismos histórico-nacionalistas actuales, nos encontramos con que no existe una unidad de comprensión plural, sino todo lo contrario, la dirección tiende hacia desigualdades cada vez más crecientes. En vez de encaminar nuestro esfuerzo a crear unas relaciones de entendimiento humano, no sólo por vía de los determinantes culturales, sino también por determinantes económicos, las relaciones con la sociedad receptora son de explotación y dominación del inmigrante.

A nadie le extraña, o por lo menos se disimula bien, conocer las diferencias en las condiciones de trabajo que existen entre personas inmigrantes y los trabajadores del país de acogida. Está claro que éstas relaciones no son igualitarias.

No sólo se necesita el pluralismo cultural para una sociedad sin conflictos, sino que es necesario también el pluralismo económico, porque parece que llamándolo sólo social no entran los parámetros del trabajo y del empleo.

A pesar de las diferentes posiciones teóricas sobre las distinciones de pluralidad, las sociedades receptoras de inmigrantes no la aplican en todo su sentido. La mayoría de éstas sociedades -entendiendo sociedad como un todo- lo que proponen es una integración casi total a 
las nornas sociales y culturales que poseen, es decir, las sociedades receptoras aceptan, rechazan o modifican los elementos procedentes de otras sociedades o culturas, para evitar, de este modo, una posible fragmentación de su unidad.

Las sociedades receptoras, ante los extranjeros, tienen unas ideas prefijadas, con frecuencia desfavorables, sobre la forma de ser de los individuos de determinados grupos. Es lo que llamamos estereotipos, que pueden ser creados por épocas históricas pasadas y se mantiene culturalmente a través de las generaciones.

A partir de este tipo de creencias, se produce la discriminación hacia los grupos en litigio, de esta manera, la discriminación no sólo es institucional, al negar la igualdad de derechos y oportunidades, sino que también es una discriminación actitudinal, al tomar la sociedad de acogida, posiciones por prejuicio hacia los «diferentes».

Algunas posiciones abogan por la palabra asimilación en tanto que otras son más defensoras del término integración. Para nosotros, serían prácticamente equivalentes.

La asimilación es un proceso que experimenta un grupo minoritario cuando -como en el caso de la inmigración - se desplaza a un país donde hay otra cultura dominante, de esta manera, la minoria es incorporada a la cultura dominante hasta que no exista una unidad cultural separada.

Las características generales de la asimilación, en el ámbito de la antropología y de otras ciencias sociales, se podrían resumir en cinco puntos, según Hunter y Whitten (1981:112):

1) es un proceso dinámico que implica necesariamente cierta medida de contacto aculturativo entre los miembros de diferentes culturas

2) la asimilación puede referirse a individuos, a grupos o a ambos.

3) la asimilación opera en sentido único. Una parte o la totalidad de una comunidad se incorpora a otra.

4) la asimilación impone cambios en importantes características del modo de ser interno y subjetivo -en nuestro caso-de los inmigrantes, es decir, que éstos deben alterar sus valores básicos y transformar eventualmente o para siempre su identidad para ser asimilados.

5) la sociedad receptora debe aceptar o adoptar de buen grado al individuo o grupo inmigrante.

Todas estas características presentan una gran variación en cuanto a cualidad, grado y cantidad. La asimilación no constituye un fenómeno del todo o nada, sino un conjunto variable de procesos concretos, los cuales implican generalmente la resocialización y la reculturación de individuos o grupos originarios de otra sociedad, que alteran su status y transforman su identidad en medida suficiente para que se les acepte plenamente como miembros de una comunidad nueva en la que 
se integran. Quizás, los antropólogos encontramos en la palabra aculturación un sentido más apropiado para el contacto entre culturas.

Entendemos por aculturación, el intercambio de rasgos culturales resultante de que los grupos estén en continuo contacto directo; los patrones culturales originales de cada uno o de ambos grupos pueden verse alterados, pero los grupos se mantienen diferentes. (Kottak, 1994:76)

Según Hunter y Whitten (1981) la aculturación larga y continuada puede conllevar la fusión de dos culturas previamente autónomas. El resultado es, en este caso, el desarrollo de un sistema cultural completamente nuevo. Algunas veces, varias culturas se atienen a un acomodo mutuo en un área que les permite persistir respectivamente en su línea distintiva, resultado que se conoce como pluralismo estabilizado; otras, los representantes de una cultura pueden llegar a identificarse con el otro sistema, a costa de un gran cambio en sus valores internos y en su visión del mundo; si son plenamente aceptados, el resultado es la asimilación.

A menudo, se han confundido aculturación y asimilación, o han supuesto que ésta es la única consecuencia del contacto cultural. Hoy día, se reconoce que ambos son procesos bastante diferentes y que, frecuentemente, de la aculturación deriva el pluralismo y de la asimilación la fusión.

Es difícil la comprensión por parte de la sociedad de acogida del fenómeno migratorio. Existen graves prejuicios y posiciones sociales ante la llegada y los posteriores contactos con gentes de otros lugares, con costumbres distintas, con gestos diferentes..., resulta negativo a los ojos de quienes los reciben, provocando actitudes de rechazo:

A los ojos del europeo común, estos personajes (los inmigrantes) - con sus características físicas diversas, su piel morena, su acento peculiar y sus ropas especiales-constituyen una invasión, un riesgo a su situación laboral, un desafio a las buenas costumbres..., la idea global sobre el Tercer Mundo legitima la conmiseración despectiva que se trata a los inmigrantes de ese origen, y la presentación de los proyectos de deculturización y asimilación a la cultura europea, como lo único posible y humanitario. (Juliano, 1993:79)

Estas actitudes de rechazo que percibe el inmigrante tienen eco en los siguientes testimonios, recogidos de entre los marroquíes que hablan el castellano más fluido:

«La emigración no beneficia a nadie, ni el país que vas ni en el nuestro porque pierdes tu forma de ser, porque aquí no eres ni marroquí ni español y en Marruecos dicen que eres un extranjero...»

«Hay ignorancia, la gente no te conoce, no sabe lo que es. La gente coge mucho de la historia, que los moros son esto o lo otro. La gente siempre saca lo que tiene de la historia, un moro mata, un moro roba..., 
eso es lo que opina la gente. Yo vi a una señora diciendo a su hijo: "corre, corre que el moro llega", igual que si el moro fuera como un monstruo. Eso lo dijo no en el sentido de que el moro es malo, no creo tampoco, pero el niño tiene siempre en la cabeza la idea de que el moro es malo. Ese niño va a educarse con esa idea, que el moro siempre es malo...»

«Si un día nos quieren conocer lo harán, aquí la gente etiqueta al marroquí: marroquí ilegal, vendedor de alfombras o gafas..., pero no es así y ahí está el problema...»

Estos testimonios nos llevan a considerar que la diferencia es difícil de comprender, aparece como una amenaza, les atribuimos comportamientos extraños que pueden llegar a las cotas más altas de peligrosidad. La convivencia con el diferente produce miedo y no permite que el inmigrante pertenezca a la comunidad donde vive, y no llegue nunca a identificarse con las gentes del lugar, o no lo dejen. La exclusión es un hecho.

El inmigrante, cuando aparece en la sociedad receptora, tiene temor y produce al mismo tiempo temor. Somos diferentes a sus ojos y son diferentes a los nuestros. El temor es mutuo, ambos nos sentimos amenazados. Temiendo la sociedad de acogida que su identidad sea anulada, intenta, por el dominio que le confiere su posición, que asimilen sus formas de vivir, antes que «ellos» nos impongan las suyas. Se tiene miedo a las aportaciones culturales y esta inquietud produce rechazos.

La convivencia entre culturas, vista desde la perspectiva de las actuales migraciones resulta de difícil realidad. Las relaciones que se establecen entre las minorías inmigrantes y la sociedad receptora están marcadas bajo el signo de la dominación por parte de esta última. Y el inmigrante lo sabe, por este motivo sus relaciones sociales se desarrollan dentro de sus propios grupos.

El inmigrante es una persona que se encuentra entre dos mundos. Su vida se desenvuelve entre la sociedad de la que procede y la sociedad de acogida. Ambas van a permanecer como dos modelos a partir del momento que tenga que quedarse en su nuevo destino y ambas van ha influir en la reconstrucción de su futura identidad, elaborando lo que podríamos llamar «su nueva cultura». Una cultura que mezclará elementos del nuevo entorno que le rodea y elementos de su lugar de origen, dando lugar a una reinterpretación de hechos culturales, sobretodo dentro de su núcleo familiar.

Los inmigrantes, vistos desde los países de acogida, se ven extraños y externos. Son grupos opuestos a las normas de la sociedad establecida, con identidades distintas que no son aceptadas y que desembocan en situaciones conflictivas. 
Estas situaciones, a las que hoy se denomina conflictos interétnicos, son las expresiones del cruce de culturas, es decir, son las diferencias culturales y sociales de los grupos que se enfrentan.

Inmigración, etnicidad y pluralismo cultural son situaciones que producen una gran preocupación social. Es con el esfuerzo de todos que deberíamos llegar al utópico y repetido pluralismo.

Es necesario, para llegar a comprender al «otro» conocer que existen otras formas de vida, de creencias, de ver la realidad..., y que ninguna debe erigirse como epicentro del mundo.

\section{BIBLIOGRAFÍA}

CHECA, F. (1993): «Los espaldas mojadas» náufragos en un mar de plástico". En Actas del VI Congreso de Antropología. Tomo 7. Pág. 39-54. Tenerife. CHECA, F. (1994): «Invernaderos e inmigrantes en el poniente almeriense».

En Actas del I Congreso Internacional de Antropología de Extremadura. (Sin publicar) Mecanografiado.

ESCARTÍN, M.J. y VARGAS, M.D. (1994): «Consideraciones acerca de los obstáculos culturales, étnicos y sociales en la comunicación entre trabajador social y clientes inmigrantes». En Actas del I Congreso Internacional de Extremadura (sin publicar).

ESTEVA FABREGAT,C. (1984): Estado, etnicidad y biculturalismo. Ed. Península. Barcelona.

GRINGERG, L. y GRINGERB, R. (1984): Psicoanálisis de la inmigración y del exilio. Ed. Alianza. Madrid.

HUNTER, D.E. Y WHITTEN, P. (1981): Enciclopedia de Antropología. Ed. Bellaterra. Barcelona.

JULIANO, D. (1991): Educación intercultural. Escuela y minorías étnicas. Ed. Eudema. Madrid.

KOTTAK, P.C. (1994): Antropología. Una exploración de la diversidad humana con temas de la cultura hispana. Ed. McGraw-Hill. Madrid.

OLIVER, M. VARGAS, M.D. y otros (1993): «Inmigración y cultura. Reflexiones críticas sobre las diferencias sociales y culturales que produce el hecho migratorio». En Alternativas, $\mathrm{n}^{\circ}$ 2, pág. 251-258. Ed. Escuela Universitaria de Trabajo Social. Universidad de Alicante.

VAN DEN BERGHE, P.L. (1971): Problemas raciales. Ed. Fondo de Cultura Económica. México.

VARGAS, M.D. y ESCARTÍN, M.J. (1994): «Inmigrantes africanos en Alicante. El trabajo como problema social». En Actas del I Congreso Internacional de Antropología de Extremadura. (Sin publicar).

VARGAS, M.D. y otros (1994): «Problemas socioculturales de la inmigración: africanos en Alicante». Beca de ayuda a la investigación del Instituto de Estudios Juan Gil Albert. Diputación de Alicante. (Sin publicar). 